\title{
PERSPEKTIF SPATIAL DALAM KAIIAN GEOGRAFI MANUSIA
}

\author{
Oleh: \\ Hastuti \\ Jurdik. Geografi, FISE UNY
}

\begin{abstract}
Abstrak
Knox, P L dan Marston SA (2004) serta de Blij dan Murphy (2003) mengemukakan pentingnya perspektif keruangan merupakan ranah epistemologi keilmuan / pendekatan untuk membedah fenomena muka bumi. Objek studi geografi meliputi fenomena muka bumi, adanya relasi timbal balik, interaksi, dan interdependensi antar fenomena (Harvey, D, 1986). Geografi meliputi geografi fisik yang mempelajari faktor fisik di permukaan bumi yang menjadi lingkungan hidup manusia dan geografi manusia mengkaji perilaku dan aktifitas manusia (Viles, $H$ dalam Castree, N; Rogers,A; dan Sherman, D, 2005). (Hagget, $P, 1984)$ menjelaskan mengenai objek formal geografi yang menekankan pendekatan dan prinsip keruangan sebagai inti dalam analisis geografi meliputi pola dari sebaran gejala tertentu di permukaan bumi (Spatial Pattern), keterkaitan atau hubungan sesama antar gejala (Spatial System), dan perkembangan atau perubahan yang terjadi pada gejala (Spatial Procces). de Blij dan Murphy (2003), awalnya menyebutkan kerangka kerja geografi adalah lima tema yakni location, interaction human and the enviroment, regions, place, and movement. Pada saat ini tema geografi yang tidak kalah penting dari kelima tema yang telah disebutkan adalah landscape (de Blij dan Murphy, 2003). Knox dan Marston (2004) menjelaskan analisis keruangan dengan memperhatikan lima konsep yakni lokasi, jarak, ruang, aksesibilitas, dan keruangan.
\end{abstract}

Kata Kunci: spatial, geografi, manusia

\section{Pendahuluan}

Tulisan ini diilhami dari pemikiran Knox, P L dan Marston SA (2004) serta de Blij dan Murphy (2003) yang mengemukakan pentingnya perspektif keruangan dalam geografi. Perspektif keruangan merupakan salah satu pendekatan geografi untuk membedah fenomena muka bumi sebenarnya merupakan ranah epistemologi keilmuan. Epistemologi sebagai cabang filsafat yang sederhana dalam rangka membangun teori dalam satu cabang keilmuan. Membangun teori diperlukan kriteria kebenaran yang utuh terpadu dan benar apabila diuji secara fungsional dalam ruang dan waktu serta memiliki koherensi, korespondensi, dan pragmatisme (Suriasumantri, 1990). Ontologi 
membahas tentang yang ada, yang tidak terikat perwujudan tertentu, yang universal (objek material). Epistemologi adalah cara memperoleh pengetahuan secara benar yang dapat dilakukan melalui deduktif dan induktif (objek formal). Aksiologi, untuk apa suatu ilmu/ kebenaran dapat bermanfaat bagi kebaikan manusia sehingga berkaitan erta dengan etika dan moral.

Menurut objek studinya geografi meliputi fenomena muka bumi, adanya relasi timbal balik, interaksi, dan interdependensi antar fenomena (Harvey, D, 1986). Geografi meliputi geografi fisik mempelajari faktor fisik di permukaan bumi yang menjadi lingkungan hidup manusia dan geografi manusia mengkaji perilaku dan aktifitas manusia (Viles, $\mathrm{H}$ dalam Castree, N; Rogers, $\mathrm{A}$; dan Sherman, D, 2005). Epistemologi digunakan untuk menjawab persoalan terkait metode dan pendekatan seperti untuk menjawab pertanyaan dimana, kapan, mengapa, dan bagaimana. Pertanyaan dimana merupakan agar dapat menunjukkan ruang atau tempat terdapatnya atau terjadinya gejala alam dan manusia. Pertanyaan mengapa merupakan agar dapat menunjukkan dan menjelaskan relasi interelasi interaksi integrasi gejala tanpa terlepas dari gejala lainnya. Pertanyaan bagaimana agar dapat menjelaskan kualitas dan kuantitas hubungan antar fenomena pada ruang tertentu. (Hagget, P, 1984) menjelaskan mengenai objek formal geografi yang menekankan pendekatan dan prinsip keruangan sebagai inti dalam analisis geografi meliputi pola dari sebaran gejala tertentu di permukaan bumi (Spatial Pattern), keterkaitan atau hubungan sesama antar gejala (Spatial System), dan perkembangan atau perubahan yang terjadi pada gejala (Spatial Procces).

\section{Tema Sebagai Kerangka Kerja Geografi}

" ......The National Geographic Society in the 1980s proposed a usefull five theme framework for geography location, interaction human and the enviroment, regions, place, and movement, and landscape" (de Blij dan Murphy, 2003). Tema location untuk menjawab pertanyaan dimana fenomena bagian muka bumi dikaji. Lokasi meliputi lokasi absolut yang dikaitkan dengan garis lintang dan garis bujur keberadaanya dimuka bumi cenderung tetap sepanjang waktu. Lokasi relatif cenderung berubah-ubah dalam periode waktu tertentu. Dalam kajian geografi lokasi absolut dan lokasi relatif memiliki peran penting ketika melakukan perencanaan wilayah. Tema place terkait dengan kajian ada apa, mengapa, dan bagaimana dengan tempat tersebut dikaitkan dengan karakteristik manusia dan krakteristik fisik sehingga menimbulkan fenomena tertentu. Fenomena dengan karakteristik yang unik ini merupakan potensi yang dapat dikembangkan untuk tujuan wisata. Karakteristik fisik termasuk didalamnya mengenai pegunungan, dataran tinggi, sungai, tanah, batuan, pantai, belantara, dataran rendah, iklim, topografi, dinamika fisik, air. Karakteristik manusia meliputi sosial, ekonomi, pendidikan, kesehatan, mata pencaharian terkait ide dan gagasan yang memunculkan fenomena tertentu. 
Mendasarkan pada karakteristik manusia ini sehingga muncul variasi fenomena perubahan lingkungan, muncul bangunan / gedung-gedung, fasilitas jalan, fasilitas restaurant, hotel, tempat hiburan, atraksi yang disuguhkan untuk pemenuhan kebutuhan wisatawan serta masyarakat di sekitar tempat pariwisata. Manusia dengan cipta rasa dan karsa dalam kajian tentang tempat ini dapat muncul pengalaman, ide, gagasan, dan kemampuan untuk menyikapi karakteristik fisik sesuai dengan perkembangan peradapan umat manusia untuk pemenuhan kebutuhan pariwisata terkait dengan perilaku, persepsi, dan penilaian tehadap karakteristik fisik. Tema human environmental interaction dalam tema ini mengandung konsep manusia melakukan adaptasi terhadap lingkungan, manusia melakukan modifikasi terhadap lingkungan dan manusia bergantung pada lingkungan. Dalam tema human environmental interaction sejalan dengan faham geografi yang telah berkembang selama ini yakni determinisme, posibilisme dan probabilisme. Faham tentang kedudukan manusia terhadap alam yakni manusia dipengaruhi atau ditentukan oleh alam dalam kehidupannya, manusia mempengaruhi atau mensiasati alam untuk kehidupannya, dan manusia dengan alam terdapat saling berkaitan sehingga muncul ketergantungan, interaksi, dan interelasi antara manusia dengan alam dalam menciptakan keselarasan di muka bumi. Tema movement meliputi perpindahan gagasan atau ide, perpindahan barang, dan perpindahan manusia. Dalam era global perpindahan gagasan, barang, dan manusia tanpa mengenal batas ruang dan waktu sehingga memunculkan persamaan dan perbedaan tentang fenomena muka bumi, dalam rangka aktualisasi manusia memenuhi kebutuhan pangan, papan, sandang, kesehatan, teknologi, dan informasi. Tema region merupakan unit dasar dalam kajian geografi saat ini sebagai pedoman analisa geografi yang menjadi ciri untuk melihat wilayah dalam kajian geografi mendasar pada formal regions, functional regions, dan vernacular regions. Wilayah berdasarkan pemerintahan, administratif, batas wilayah fisik mendasarkan pada kenampakan fisik, berdasarkan pada fungsi tertentu seperti pelayanan komunikasi, pelayanan ekonomi, pelayanan sosial serta berdasarkan persepsi yang diciptakan manusia seperti arah atau tujuan tertentu bagian barat, timur, sebelah selatan.

de Blij dan Murphy (1992), awalnya menyebutkan kerangka kerja geografi adalah lima tema yakni location, interaction human and the enviroment, regions, place, and movement. Pada saat ini tema geografi yang tidak kalah penting dari kelima tema yang telah disebutkan adalah landscape (de Blij dan Murphy, 2003). Landscape telah menjadi konsep penting dalam geografi sejak tahun 1982 ketika Otto Schulter professor dari Berlin mencari jalan keluar dari geografi determinisme (memandang hubungan manusia dengan lingkungan / human interaction yang menekankan dominai peran lingkungan terhadap kehidupan manusia). Geografi determinisme telah dipopulerkan pendahulu Otto Schulter yakni Frederich Ratzel (tokoh geografi 
dari jerman) yang menganut paham geografi determinisme. Otto Schulter mempopulerkan geografi kebudayaan dengan objek utama landscaft (Sauer, C 0,1996). Sauer menggambarkan landscape sebagai berikut

\section{FACTORS}

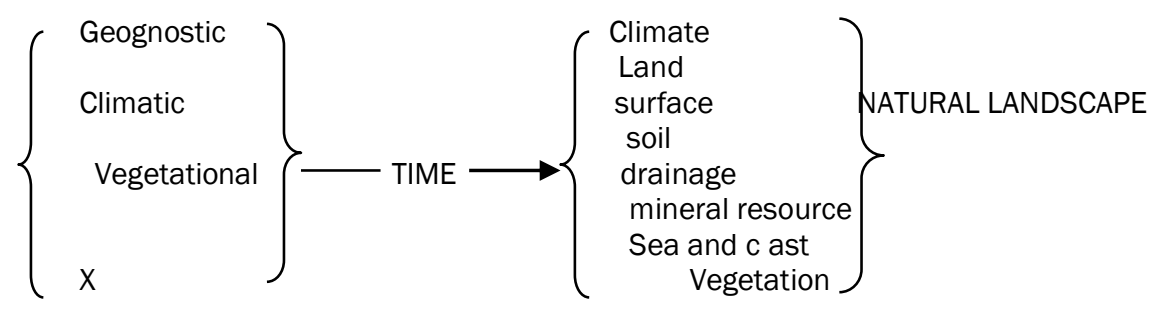

Gambar: Natural Landscape dari Carl O sauer

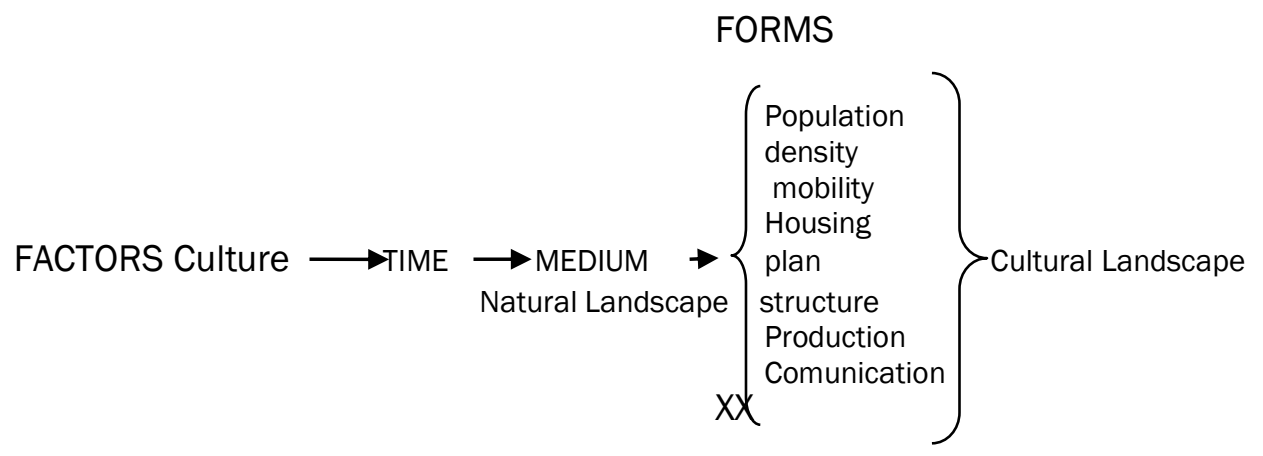

Gambar: Cultural Landscape dari Carl O sauer

Berbeda dengan de Blij dan Murphy ketika menjelaskan kerangka kerja geografi dengan analisis keruangan yang memperhatikan tema-tema. Knox dan Marston menjelaskan analisis keruangan dengan memperhatikan lima konsep yakni lokasi, jarak, ruang, aksesibilitas, dan keruangan. Studi mengenai fenomena geografi dapat menggunakan terminologi untuk menyusun titik, garis, area atau permukaan kedalam peta. Analisis keruangan meliputi lokasi jarak, ruang, aksesibilitas, dan interaksi keruangan merupakan lima konsep kunci analisis keruangan meskipun masih memerlukan elaborasi.

“.......Location, distance, space, accessibility, and spatial are five concepts that are to spatial analysis (Knox, PL dan Marston SA, 2004). Lokasi penting perannya untuk mengungkapkan terminologi ketika memberi nama wilayah dan 
tempat. Lokasi dalam konsep absolut, bahwasanya lokasi secara nyata digambarkan dalam koordinat garis bujur dan lintang. Latitude menggambarkan jarak antara dua titik di muka bumi untuk mengukur dalam menit, detik antara utara selatan dan ekuator yang mana dengan 0 derajat. Garis bujur disebutkan sebagai jarak pada titik dimuka bumi dalam menit, detik antara timur dan barat dan meredian utama. Saat ini Geography Position System (GPS) mempermudah dalam penentuan garis lintang dan garis bujur pada setiap titik.

GPS didukung 21 satelit ditambah 3 perangkat orbit untuk menghitung letak satu titik dimuka bumi yang terpercaya untuk menentukan waktu. GPS merupakan cara mengumpulkan data spatial yang lebih handal dan efisien. Merupakan kombinasi GIS dan remote sensing, GPS merupakan revolusi untuk membuat peta dan analisa keruangan. Lokasi relatif untuk meyakinkan dengan terminologi site dan situasi (Knox, PL dan Marston SA, 2004).

Site merupakan atribut fisik dan lokasi terkait dengan bentang alam, tanah, vegetasi, dan sumberdaya air. Situasi untuk mengemukakan lokasi yang mewakili lokasi relatif pada suatu tempat dengan tempat lain yang ditandai dengan aktifitas manusia seperti aksesibilitas jalur jalan. Lokasi merupakan dimensi kognitif untuk menjelaskan wilayah dan tempat yang memadukan pengetahuan pengalaman dan kesan. Representasi ini mendasari penjelasan secara langsung tertulis dengan aktualisasi lokasi. Lokasi merupakan gambaran kognitif yang disampaikan untuk informasi tentang lingkungan dan penduduk.

Jarak digunakan untuk mengukur absolut fisik dalam unit meter, kilometer atau mill. Pengukuran jarak relatif dikemukakan dalam ukuran waktu, biaya, dapat ditempuh dengan lebih banyak atau sedikit waktu dalam jarak 10 $\mathrm{km}$ dari titik satu ke titik lain dibanding dengan jarak sama $10 \mathrm{~km}$ dari titik satu ke titik lain terkait dengan ongkos. Jarak merupakan faktor terpenting yang dapat menentukan hubungan timbal balik secara nyata sebagai tema pokok dalam geografi. Hal ini dapat dipaparkan dengan hukum pertama dalam geografi.

Setiap hubungan terkait dengan faktor lain dapat lebih dekat atau lebih jauh bergantung pada sesuatu. Waldo Tobler ahli geografi dari Universitas California Santa Barbara mengemukakan bagaimana penelitian tentang pergeseran jarak. Jarak ditentukan oleh adanya kegiatan manusia yang bergeser dari waktu ke waktu tergantung waktu tempuh dan ongkos tempuh. Apa yang dikemukakan ahli geografi tidak sama bahwa jarak bergantung pada beberapa faktor yang digunakan untuk menentukan jauh dan dekat terutama jarak relatif (Knox, PL dan Marston SA, 2004).

Ruang memiliki perspektif relatif dan absolut. Perbedaan untuk analisa ruang dalam geografi manusia ditunjukkan tabel di bawah ini. 


\begin{tabular}{|c|c|c|c|}
\hline $\begin{array}{c}\text { Ruang absolut/ } \\
\text { Ruang matematika }\end{array}$ & $\begin{array}{c}\text { Ruang relatif/ ruang } \\
\text { sosio ekonomi }\end{array}$ & $\begin{array}{c}\text { Ruang relatif ruang } \\
\text { budaya }\end{array}$ & $\begin{array}{c}\text { Ruang kognitif ruang } \\
\text { perilaku }\end{array}$ \\
\hline Titik & Site & Tempat & Bataslahan \\
\hline Garis & Situasi & Jalan & Jalan kecil \\
\hline Area & Rute & Teritorial & Distrik \\
\hline Datar & Wilayah & Bidang & Lingkup \\
\hline konfigurasi & sebaran & dunia & Layout keruangan \\
\hline
\end{tabular}

Sumber : Knox, PL dan Marston SA, 2004

Ruang absolut merupakan penjelasan untuk kenampakan berupa titik, garis, area, dataran, dan konfigurasi hubungan timbal balik. Pengukuran relatif dapat membentuk ruang sosio- ekonomi atau ruang budaya. Ruang sosioekonomi dapat untuk menjelaskan pengukuran site dan situasi, rute, wilayah, dan pola-pola persebaran. Pengukuran hubungan spatial untuk mengukur waktu, ongkos, keuntungan dan produksi untuk mengemukakan jarak fisik. Hasil dari konfigurasi interaksi spatial antara fenomena alam, manusia, dan lingkungannya dalam perspektif keruangan dapat digambarkan dengan memanfaatkan peta. Peta menjadi sarana dan hasil penggambaran keruangan yang sangat penting ketika menjelaskan variasi, perbedaan, dan persamaan fenomena muka bumi.

Aksesibilitas untuk mengukur lokasi relatif; kesempatan untuk berhubungan dari satu titik ke titik atau lokasi dalam kaitan dengan lokasi lain. Aksesibilitas untuk memperkirakan jarak yang lebih dekat terhadap sesuatu yang mempengaruhi perilaku penduduk. Konektifitas juga penting sebagai aspek untuk aksesibilitas karena hubungan dan interaksi yang bergantung pada hubungan komunikasi dan transportasi; jalan; jalan raya, sambungan telepon, gelombang. Aksesibilitas memiliki fungsi ekonomi, budaya dan ukuran jarak yang jauh lebih penting dari jarak absolut. Hubungan antara tempat dan wilayah berlangsung oleh adanya perpindahan. Interaksi keruangan untuk menjelaskan pergerakan dan perpindahan aktifitas manusia, perpindahan, perjalanan belanja, telekomunikasi, transfer tunai elektronik, migrasi, dan perjalanan liburan. Prinsip dasar dari interaksi keruangan meliputi empat konsep dasar complementary, transferability, intervening opportunity, dan diffution

Kondisi yang diperlukan untuk melengkapi satu tempat / place untuk interaksi keruangan antar dua tempat harus membutuhkan tempat lain meliputi antara lain lingkungan fisik, sumberdaya fisik, pemenuhan kebutuhan manusia (pangan, sandang, hiburan), dan sumberdaya manusia. Komplementer ini dapat untuk menjelaskan aliran wisatawan, pembagian kerja, aliran sumberdaya, aliran komunikasi dan masih banyak lagi kegiatan di muka bumi antarsatu tempat dengan tempat lain. Transferability menjadi kondisi penting dalam perbedaan jarak karena adanya pemberian atau fungsi 
pergerakan ongkos dari waktu dan uang. Pemindahan pada moda transportasi dan komunikasi, sebagai contoh produksi dari eksplotasi sumberdaya dipindahkan dengan kapal kereta, buah-buahan, dan produk lainnya dalam keadaan segar yang memerlukan transportasi, komunikasi, komputer, monitoring serta alat elektronik lain.

Kesempatan antara (intervening opportunity) sebagai prakondisi interaksi keruangan, kesempatan antara dapat menentukan volume dan pola perpindahan serta aliran barang, manusia, dan gagasan. Kesempatan antara dapat dimanfaatkan untuk menentukan arah pergerakan yang memudahkan pergerakan/ perpindahan keadaan antara dua titik, luas, dan alternatif arah yang relatif penting merupakan konsep kesempatan antara yang menjadi bagian penting dalam perpektif keruangan geografi.

Difusi keruangan digunakan untuk mendeskripsikan aliran ketika merebaknya penyakit, perkembangan inovasi teknologi, perkembangan politik, dan aliran musik baru yang merupakan bagian dari fenomena pada tempat dan ruang tertentu. Analisa Hagerstrand mengenai difusi keruangan terdapat enam unsur yakni area, waktu, objek, tempat asal, tempat tujuan, dan jalur (Hagerstrand, 1999).

\section{Perspektif Keruangan Geografi Manusia}

Objek material bidang kajian studi geografi meliputi bumi yakni menciptakan kekuatan alam dan memodifikasi dengan kegiatan manusia dibedakan dalam dua cabang yakni kajian mengenai fenomena fisik dan manusia (Knox, P L dan Marston S A, 2004). Geografi manusia menyangkut organisasi keruangan dari kegiatan manusia dan hubungan timbal balik penduduk dengan lingkungannya. Perhatian utama geografi manusia tidak dapat dilepaskan dari lingkungan alam dalam pengaruhnya dengan kegiatan manusia. Kajian geografi manusia meliputi kenampakan muka bumi secara luas seperti produksi pertanian dan keamanan pangan, perubahan penduduk, penyakit, management sumberdaya, lingkungan maupun pencemaran lingkungan, perencanaan wilayah, dan simbul dari tempat dan bentang lahan (Knox, P L dan Marston S A, 2004).

Cara pendekatan geografi manusia dengan memperhatikan aspek keruangan menjadi bagian penting untuk mengkaji bagaimana hubungan antara unsur alam, sosial, ekonomi, politik,dan budaya, fenomena, sosial, ekonomi, politik, dan budaya. Sebagai contoh dalam geografi manusia tidak hanya mengkaji tentang pola dari produksi pertanian tetapi juga hubungan timbal balik dan saling bergantung sebagai sebab akibat dari unsur-unsur geografi. Geografi manusia tidak hanya mengkaji bagian wilayah pertanian tetapi juga hasil pertanian seperti produksi pertanian di suatu wilayah yang memiliki bentanglahan dan budaya berbeda. 


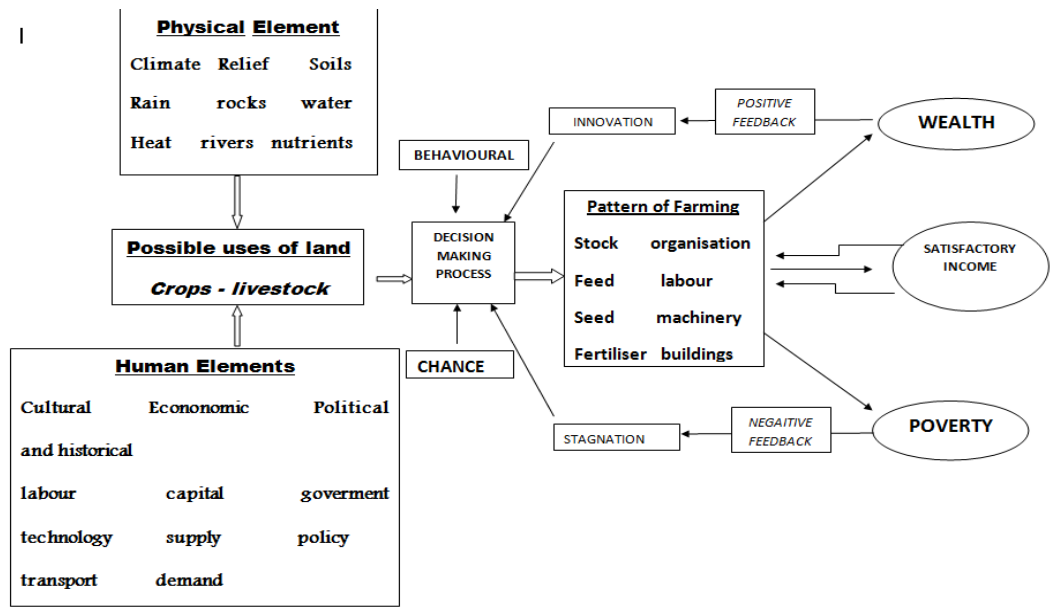

Sumber : Element Of Human Geography, Hammond dan Whynne, Charles, 1979

Studi geografi manusia agar dapat dijelaskan dengan konsep dasar diaplikasikan bukan hanya untuk kajian pertanian tetapi untuk berbagai kajian tentang kegiatan manusia di muka bumi. Studi mengenai fenomena geografi dapat menggunakan terminologi untuk menyusun titik, garis, area atau permukaan kedalam peta. Dalam analisis keruangan meliputi lokasi jarak, ruang, aksesibilitas, dan interaksi keruangan merupakan lima konsep kunci analisis keruangan. Geografi mengetahui dan menjelaskan tentang pola lokal dalam menentukan prinsip dasar dalam pengaruh ekonomi lokal dan selanjutnya sebagai prinsip dasar dalam geografi manusia adalah memperkirakan kegiatan manusia dalam dimensi ekonomi. Kumpulan hasil untuk menentukan cara melalui prinsip dasar dari komersial dan lokasi industri serta interaksi yang memiliki sumbangan penting dan pola- pola masa kini dalam geografi manusia. Knox, PL dan Marston SA, 2004 menentukan lokasi secara nyata dalam kaitan dengan geografi yang berbeda menumbuhkan struktur keruangan meliputi:

- Aksesibilitas adalah ketersediaan input meliputi bahan mentah dan energi.

- Tenaga kerja dengan keahlian/ skill tertentu

- Biaya untuk melakukan proses meliputi ongkos untuk pengadaan lahan, gedung, mesin produksi, perangkat keras / hardware, perangkat lunak / software, pemeliharaan, beban kerja, upah, uang tunai, dan biaya lokal. Pasar untuk penjualan produksi dan pemenuhan kebutuhan lainnya.

- Biaya untuk transportasi ketika diperlukan biaya perjalanan menuju lokasi alternatif, biaya untuk pengepakan, perlindungan.

- Pengaruh dari budaya dan faktor kelembagaan, kebijakan, kesempatan kerja baru yang tercipta dari linkage industri

- Pengambilan keputusan individu 
Beberapa aspek geografi manusia tersebut dalam perspektif keruangan yang terpenting adalah bagaimana fenomena kegiatan manusia tersebut dapat digambarkan dalam peta dengan pemanfaatan SIG agar dapat untuk mengungkap kegiatan manusia sebagai aspek kajian geografi manusia. Variasi, perbedaan, dan persamaan kegiatan manusia di muka bumi sehingga melahirkan adanya interaksi. Interaksi dalam perspektif keruangan inilah yang dikaji sebagai geografi manusia untuk selanjutnya dapat digambarkan melalui peta.

Pendekatan keruangan menekankan analisisnya pada variasi distribusi dan lokasi dari pada gejala gejala atau kelompok gejala gejala di permukaan bumi contoh yang di kemukakan oleh Petter Hagget misalnya studi variasi kepadatan penduduk, studi variasi penggunaan lahan, studi variasi tentang kemiskinan di perdesaan. Faktor faktor yang menyebabkan pola pola distribusi keruangan yang berbeda beda dan bagaimana pola pola keruangan yang ada dapat di ubah sedemikian rupa sehingga distribusinya menjadi lebih efektif. Pendekatan keruangan menyangkut pola, proses, dan struktur di kaitkan dengan dimensi waktu maka analisisnya bersifat horizontal.

The spatial perspective is geogaphy's unifying bond and is demonstrated through the use map. Maps are use to portray the distinctive character of places; their relationship to environment issues, the movements of people, goods, and ideas; and regions of various type People's perception of places and regions are influenced by their individual mental maps as well as by printed maps (de Blij dan Murphy, 2003). Perpektif keruangan dalam geografi akan tampak lebih jelas ketika dituangkan dalam peta. Peta dapat digunakan untuk menggambarkan adanya variasi, perbedaan, persamaan muka bumi meliputi aspek fisik dan non fisik. Perbedaan persamaan dalam terkait dengan lokasi, tempat, interaksi antara manusia dengan lingkungannya, perpindahan barang, manusia, dan gagasan, serta variasi wilayah maupun bentanglahan dapat digambarkan melalui peta seperti peta aliran barang, peta aliran manusia / penduduk, peta aliran informasi.

\section{Penutup}

Perspektif keruangan merupakan ranah epistemologi keilmuan/pendekatan untuk membedah fenomena muka bumi. Objek studi geografi meliputi fenomena muka bumi, adanya relasi timbal balik, interaksi, dan interdependensi antar fenomena. Geografi meliputi geografi fisik yang mempelajari faktor fisik di permukaan bumi yang menjadi lingkungan hidup manusia dan geografi manusia mengkaji perilaku dan aktifitas manusia. Objek formal geografi yang menekankan pendekatan dan prinsip keruangan sebagai inti dalam analisis geografi meliputi pola dari sebaran gejala tertentu di permukaan bumi (Spatial Pattern), keterkaitan atau hubungan sesama antar gejala (Spatial System), dan perkembangan atau perubahan yang terjadi pada 
gejala (Spatial Procces). Kerangka kerja geografi adalah lima tema yakni location, interaction human and the enviroment, regions, place, and movemen, dan. Landscape. Analisis keruangan dengan memperhatikan lima konsep yakni lokasi, jarak, ruang, aksesibilitas, dan keruangan. Hubungan antara tempat dan wilayah berlangsung oleh adanya perpindahan. Interaksi keruangan untuk menjelaskan pergerakan dan perpindahan aktifitas manusia, perpindahan, perjalanan belanja, telekomunikasi, transfer tunai elektronik, migrasi, dan perjalanan liburan. Prinsip dasar dari interaksi keruangan meliputi empat konsep dasar complementary, transferability, intervening opportunity, dan diffution. Perpektif keruangan dalam geografi akan tampak lebih jelas ketika dituangkan dalam peta, untuk menggambarkan adanya variasi, perbedaan, persamaan muka bumi meliputi aspek fisik dan non fisik.

\section{Daftar Pustaka}

Ajang Pinem (1995). Konsep Kelembagaan Sistem Informasi Geografis Tata Ruang (makalah seminar). Yogyakarta: Fakultas Geografi UGM

Cook, R.U. dan Doornkamp, J.C. (1994). Geomorphology in Enviromental Management - and New Introduction. Amsterdam: Elsevier.

Heri Tjahjono. (2003). “ Kerentanan Medan Terhadap Longsoran dan Stabilitas Lereng di Daerah Kecamatan Gunung Pati Kota Semarang" Suatu Aplikasi Pendekatan Survey Medan)" Tesis. Yogyakarta: Program Pascasarjana Universitas

Pusat Studi Bencana Alam UGM dan Bappeda Kabupaten Kulon Progo. (2001). Penyusunan Sistem Informasi Penanggulangan Bencana Alam Tanah Longsor di Kabupaten Kulon Progo. Yogyakarta:PSBA UGM.

Sitanala Arsyad. (1989). Konservasi Tanah dan Air. Bogor: Penerbit IPB

Sudibyakto. (1985). Mitigasi Bencana Alam Gunung Berapi. Yogyakarta:Andi Offset.

Sukendra Martha, M.Sc. MApp.Sc. (1995). Rujukan Informasi Spasial untuk Menunjang Keberhasilan Pembangunan Daerah (makalah seminar). Yogyakarta: Fakultas Geografi UGM

Sutikno. (1994). "Pendekatan Geomorfologi untuk Mitigasi Bencana Alam Akibat Gerakan Massa Tanah atau Batuan". Prosiding di UGM, 16-17 September. Yogyakarta:Fakultas Geografi UGM.

(2002). " Evaluasi Tingkat Bahaya Tanah Longsor Kabupaten

Kulonprogo Daerah Istimewa Yogyakarta". Prosiding di UGM, 12-13 Maret, Yogyakarta: PSBA UGM. 